\title{
The relationship of atmosphere, satisfaction, and loyalty: Sample of a fitness center
}

\author{
Mehmet OZTAS', Ali SEVILMIS², Erkan Faruk SIRIN² \\ ${ }^{1}$ Erzincan University, School of Physical Education and Sports, Erzincan, Turkey \\ ${ }^{2}$ Faculty of Sport Sciences, Selçuk University, Konya, Turkey. \\ The paper presented orally at the $3^{\text {th }}$ International Sports Sciences Tourism and Recreation Student Congress, 27-29 May, Gaziantep Turkey. \\ Address Correspondence to A. Sevilmiş, e-mail: alisevilmis.42@hotmail.com
}

\begin{abstract}
In the recent years, that fitness market rapidly grows, understanding of its importance and change of suggestions according to demand also revealed the importance of intangible elements as well as tangible elements. The aim of this study is to measure the relationship of atmosphere, satisfaction, and loyalty the customers, who are member to a private fitness center, perceive from this center. The study group consists of 503 participants ( $\mathrm{n}_{\text {male }}=465$; nfemale $=38$ ), who are at least for six month to a private fitness center, with convenience sampling method. In this study, "Personal Information Form", "Perceived Leisure Time Loyalty and Leisure Time Satisfaction Scale", and "Fitness Center Atmosphere Scale" were utilized. In the analysis of data, correlation and regression analysis was used for examining the relationships between the variables and explanatory factor analysis for fitness center scale. As a result of the analyses, it was identified that fitness center atmosphere affected customer satisfaction and, satisfaction, customer loyalty. This study can cause the importance of atmosphere in the behaviors of customer satisfaction and loyalty to be better understood.
\end{abstract}

Keywords: Fitness centers, fitness center atmosphere, customer satisfaction, customer loyalty.

\section{INTRODUCTION}

Fitness market rapidly growing in the world, as in all over the world, also has a large market share in Turkey. About annual Euro 910 million of sale is realized through finance centers in Turkey (22). That fitness market structure is so large led healthy life and fitness centers to consider intangible elements as well as tangible elements. For being able to meet the demands the significant growth in fitness market brings, placing the desires and needs of customers in the center of marketing strategies of sport businesses has a great importance. Sport businesses want their existing customers to make loyal. Customer loyalty is a key element for being able to fully use sale potential and enlarge market share in competition $(5,6)$. There are many applications in practice to provide customer loyalty. Gaining customer and enhancing the loyalty of available customer also take place in the center of businesses $(10,30)$. For enabling customer loyalty to characteristically to be increased, many methods and instruments are used (32) these methods and instruments have a gradually increasing importance in businesses $(7,40)$. What underlying this change is how the tangible as well as intangible elements are perceived $(18,19,48)$. With a different saying, that the tangible as well as intangible elements are shaped in a customeroriented way has an importance that cannot be underestimated for sport businesses.

The previous studies $(2,33,38,44,50)$ dealt with the importance of especially service quality of sport centers in fitness service sector and identified that service quality from the viewpoint of customer had an important effect on customer satisfaction (42), and loyalty and quality, on the satisfaction and behavioral intention of customers (1). Nowadays, in healthy life and sport centers, it is much more paid attention increasingly to not only to pricing their own programs but also to the issue of providing an enjoyable and exciting medium or atmosphere of physical activity. Such an interest is accepted as much more necessary in sport service industry, because the services is intangible at high degree and customer generally experiences a service and, in physical environment, reach a conclusion related to service quality from spatial esthetics and tangible cues in atmosphere (20). 
In forming atmosphere of health life and sport centers, the factors, which are used the most effectively, and have the largest share, are the physical ones. However, it is necessary not to definitely ignore the factors, which address to the senses and emotions of people. With the development of marketing, trade, world economy and people (13). It is suggested that the emotional factors stand out in shopping. For example, as a result of the studies carried out together by Service Industry Research Systems and The Gallup Organization, while $76 \%$ of the consumers in US made a decision where they will shop mostly behave with the effect of emotional factors (36). In the area of environmental psychology, many studies were carried out regarding that the environment and environmental problems affected the emotions of individuals and that their behaviors are shaped as a result of this. Therefore, differently from the physical factors, the importance of sensory factors, on which there is no much research will be increasingly understood. When considered in this context, the sensory factors (the ones related to the voice, touching, and feeling) that form atmosphere are seen as important in terms of fitness centers wanting competitive advantage

While Kotler defines service area atmosphere as "effort to design the purchasing environment for producing the certain emotional effects on the purchaser, whose purchasing probability is increasable" (31), Bitner (9) defines it as "an environment, in which the services are transmitted and business and consumers pass to interaction". Service area atmosphere is a combination of both tangible (decoration, employees, etc.) and intangible (temperature, color, etc.) environmental elements (34). Just as also expressed with the terms such as "atmosphere, design, and exhibition" in sport centers, time is also expressed the esthetics of environment (1). Manager of fitness center can use these factors such as sound level, decoration, temperature, cleanness, smell, lightning, color, and music making contribution to the medium atmosphere before and during buying service in such a way that sometimes one of them (music, smell, and etc.) will be stimulator, sometimes some of them, and rarely all of them for them to make a contribution to service quality.

In the studies, there is no a only one sizing taken as reference regarding service area atmosphere. The studies shows that the dimensions of service area atmosphere and/or its sub dimension affect the consumer emotions and that these emotions affected via service area atmosphere purchasing behaviors of consumers. The findings obtained point out how much important subject service area atmosphere is for both retailing sector and service sector (4).

Today and in the future, one of those benefiting from sport and sport managers will be you maintain social interest toward sport and sportive activities. (27). The most basic way of being able to maintain this interest is to be able to meet the expectations and needs of sport consumer, because it is known that the tendency of consumer, whose expectations and needs are met at the high level, to become loyal increases and that the increasing loyalty also affects the purchases in the future period and, depending on this, that interest toward sport centers $(12,15,46)$. Fitness centers having high share in sport economy, for being able to survive in intensive competition and have a share from the cake, are in the position of providing customer satisfaction with completely customer oriented services (39). Provided that customers are satisfied with the sport centers they participate in, since they will continue to go to that service and recommend it to their friends and relations, one should be paid attention to the presentation of the products, services, and activities. So, meeting the expectations of customers is important in terms of both keeping in hand the existing customers and becoming member of new customers to that center $(21,28)$.

According to Oliver (37), loyalty is defined as "consistently reburying a preferable product or service in the future as well and feeling a deep loyalty toward becoming continuous customer of it and, thus, despite the efforts of another brand to market itself and situational factors, repeatedly buying the same brand or group of the same group". In addition, Oliver (37) thinks of that there is a very strong relationship between customer satisfaction and loyalty and satisfaction is a determinative element in realizing the satisfaction

It is remarkable lack of studies toward accounting for the relationships customer satisfaction and customer loyalty related to healthy life and sport (fitness) centers Among these studies, Howat et al. (21), in the study they carried out on the customers of sport and recreation centers, revealed that customer satisfaction positively affected the recommendation of the product or service to the other consumers. In another study, Yildiz (51) identified that in fitness centers, customer 
satisfaction is an important determinant of customer loyalty. Katırcı \& Oyman (26) determined a positive and significant linear relationship between the perceived satisfaction and loyalty tendency in sport centers. Biscaia et al. (8), in their studies, in which they examined the effects of emotions on the satisfaction and behavioral loyalties of soccer spectators, they identified that only the emotion joy had a direct effect on satisfaction and that through satisfaction it had an indirect effect on behavioral loyalty. For soccer spectators to have an enjoyable experience, they talked about that it is necessary to change stadium atmosphere and social possibilities to develop.

All over the world, fitness centers send millions for advertisement campaigns. Fitness centers gain favor less or more from these advertisement campaigns. That fitness center keeps its existing customers with certain possibilities is less costly than their acquiring new customers. "Well, why does a person wanting member to fitness center select prefer your center"? The answer of this question makes think of that the center depends on tangible elements as well as intangible elements.

In sport service sector, although any study is met on the atmosphere of sport center, in retailing and restaurant sector, the studies carried out to discover the effects of atmosphere on consumer behaviors and satisfaction are met $(16,20,45)$. Especially, in sports centers, the effect of atmosphere, which can be evaluated on the intangible elements, is not known. For example, there are limited number of empirical study to discover the effects of perceptions such as the smell of sport center, playing music and lightning, colors used, and etc. on satisfaction and loyalty and satisfaction, on loyalty.

In this direction, the aim of the study is shaped with the relationship of atmosphere, satisfaction, and loyalty. In the center of the study, it is mentioned about that the effect of atmospheric elements on customer satisfaction and customer satisfaction on loyalty. The target is to reveal that the characteristic features of customers of fitness and healthy life center about fitness center atmosphere. The aim, measuring the relationship of atmosphere, satisfaction, and loyalty that customers of fitness center from that center, is to make contribution to the area.

\section{MATERIAL \& METHODS}

In this study, in order to examine the relationship of atmosphere, satisfaction, and loyalty the customers, who are member to a private fitness center, perceive from that center, in the scope of quantitative paradigm, relational scanning model was used. The study examining the relationships and relation is mostly called as relational study (11). Relational studies are the study models aiming at identifying the presence and/or degree of together variation between in two or more number of variables (25).

Considering that combining customer behaviors in a single model with the concepts of atmosphere, satisfaction, and loyalty will enable them to be better estimated, in Figure 1, the model of the study is presented.

The study model includes three variables related to the customers of fitness center as atmosphere, customer satisfaction, and customer loyalty. As seen in the study model, [this study] is toward measuring the relationship of the atmosphere, satisfaction, and loyalty [the customers] perceive from the fitness center.

The scope of the study was formed by considering a large scale fitness center, which has a high quality medium. The study was limited with the participants, who are the member to the fitness center determined for at least 6 months. In obtaining the data, study method was used and convenience sampling methods among sampling methods.

\section{Atmosphere}

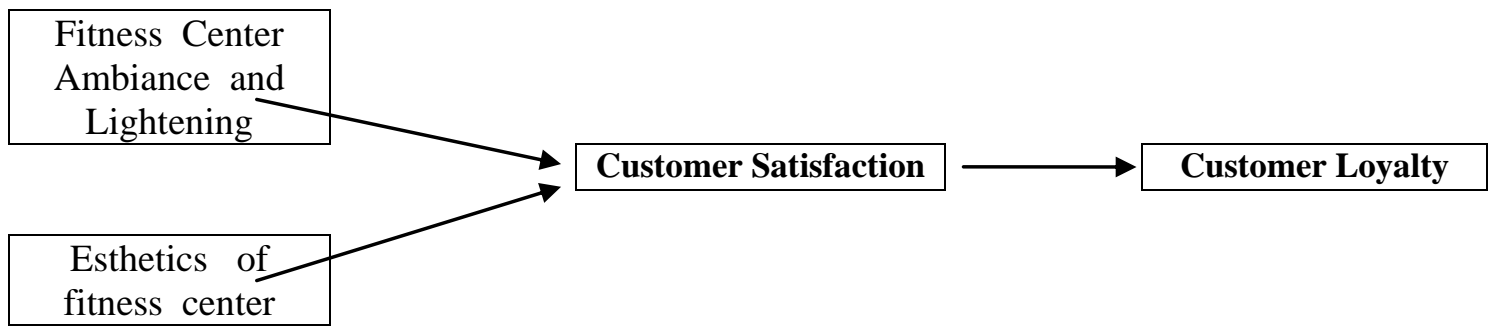

Figure 1. Study model. 


\section{Participants}

The sample of the study consists of 503 participants regularly getting service in the centers [which can give at least 3 sport service (swimming pool, fitness, sauna, etc.), whose personnel number is more than 20, and which has at least 20 members] presenting sport and fitness service in Konya City and voluntarily participating in the study. The survey study was carried out between the dates of August 1-October 30, 2015. As a result of eliminating uncompleted questionnaire, 503 questionnaire were included in assessment

The demographic characteristics of those participating in the study were presented in Table 1.

Table 1. The demographic features of the participants.

\begin{tabular}{lcc}
\hline Variables & $\mathrm{f}$ & $\%$ \\
\hline Gender & 38 & 7.6 \\
Woman & 465 & 92.4 \\
Man & & \\
\hline Age & 131 & 26.0 \\
18-25 aged & 233 & 46.3 \\
26-35 aged & 104 & 20.7 \\
$36-45$ aged & 31 & 6.2 \\
$46-55$ aged & 4 & .8 \\
56 aged and older & & \\
\hline Civil Status & 263 & 52.3 \\
Bachelor & 240 & 47.7 \\
Married & & \\
\hline Monthly Income & 110 & 21.9 \\
TL 1000 and less & 127 & 25.2 \\
TL 1001-2000 & 127 & 25.2 \\
TL 2001-3000 & 73 & 14.5 \\
TL 3001-4000 & 66 & 13.1 \\
4001 TL and more & & \\
\hline Education Status & 31 & 6.2 \\
Primary School & 45 & 8.9 \\
Secondary School & 196 & 39.0 \\
High School & 207 & 41.2 \\
Undergraduate & 24 & 4.8 \\
Postgraduate & & \\
\hline Frequency of Use & 16 & 3.2 \\
One time a week & 79 & 15.7 \\
2 times a week & 192 & 38.2 \\
3 times a week & 142 & 28.2 \\
4 times a week & 54 & 10.7 \\
5 times a week & 16 & 3.2 \\
6 times a week & 4 & .8 \\
\hline times a week & 503 & 100.0 \\
\hline Total & & \\
\hline & & \\
\hline & & \\
\hline & & \\
\hline & & \\
\hline
\end{tabular}

$7.6 \%$ of fitness center customers participating in the study are consist of female members and their $92.4 \%$, male members. It is understood that customers participating in the study are predominantly in the range of ages 26-35 and that they consist of the single people in the rate of $52.3 \%$.
The majority of customers participating in the study $(50.4 \%)$ have an income in the range of 1001-3000. It is seen that the customers included in the sample of the study are predominantly consist of the individuals having education at undergraduate level $(41.2 \%)$. When a total of 503 customers of fitness center participating in the study are examined according to the frequency of use, it is seen that those using sport center 3 times a week form the largest group with the rate of $38.2 \%$, while those using sport center 7 times a week form the smallest group with the rate of $8 \%$.

\section{Measures}

While questionnaire is formed, "Leisure Time Loyalty and Leisure Time Satisfaction Scale", developed by Yetim (49) was used. In addition, "Fitness Center Atmosphere Scale", after the studies of reliability and validity were carried out, were developed by the researchers.

In order to assess the cases of leisure time loyalty and leisure time satisfaction of participants, who are member to fitness center, "Perceived Leisure Time Loyalty and Leisure Time Satisfaction Scale", developed by Jung (23) and adapted by Yetim (49), was used. Scale has two sub dimensions and consists of 16 items. While leisure time loyalty consists of 10 expressions, leisure time satisfaction constitutes the remaining 6 expressions. The first factor was named as "loyalty" and the second factor as "satisfaction". In order to group, classify, and transform these expressions into the main factors, explanatory factor analysis was applied. KMO is 0.924 and BTS is $5152.084(p<0.01)$. Two factors classified account for $60.225 \%$ of total variance. As a result of factor analysis carried out, total reliability of two expressions (Cronbach alpha $=\alpha$ ), divided into two factors, was found as 0.92 . While the reliability coefficient regarding to the first factor is 0.898 , reliability coefficient regarding the second factor is 0.887 .

"Fitness Center Atmosphere Scale", which aims to measure customer perception during activity in fitness center, was prepared by being based on the study carried out by Ünal et al. (47) and as a result of pre-interviews made with the individuals that are member to two sport centers. The facility esthetics consists of two sub dimensions as ambiance and lightening and 10 expressions forming these dimensions. In this analyzes analyses of main components and Varimax rotation options were used as explanatory model (Table 2). 


\section{Procedures and data analysis}

The data were obtained, after the necessary permissions are taken from fitness center management in 2015, administering the data, personal information form, and scales to the customers of fitness center before or after training. Before administrating, the necessary explanations were made by the researcher about the aim of the study. Completing the questionnaires of data collection was voluntarily carried out by the customers. Completing data collection instruments took about 15 minutes. After excluding the forms, which are completed in missing or wrong way, 503 forms in acceptable quality were made ready for analyses.

In the stage of analysis of data, in compatible with the results of the study, the frequency and percentage distributions describing personal characteristics of the members of healthy life and sport center, which consist of sample group, were derived. For the reliability analysis of the variable in the quality of scale, Cronbach's Alpha test was utilized. For the expressions regarding fitness center scale, factor analysis was applied. In order to assess the relationship between the variables, correlation and regression analyses were applied. The data obtained were analyzed by SPSS (Statistical Package for Social Scientists for Windows Release 20, 0) program in computer and its significance was tested at the level of 0.05 .

\section{RESULTS}

\section{Factor analysis of fitness center scale}

Factor analysis was applied to the scale used to measure fitness center atmosphere, It was observed that the data showed a normal distribution. In the analyses, as explanatory mode, main components analysis and Varimax rotation options were used. First of all, it is regarded to Cronbach alpha values of the variables taking place in the scale and the coefficients of the relationship between variables. As seen in Table 2, as a result of factor analysis, fitness center factors scale consists of 8 item and 2 dimensions. In the direction of the meanings the items in the factors, Factor 1 was named as Lightening and Ambiance and Factor 2 as Facility Eutectics.

As a result of factor analysis applied, a total of two items, one of which is from the dimension of facility esthetics, whose factor load remains below 40 and one from dimension of ambiancel lightening were excluded from analysis. In general, the rate of two factors to account for total variance was obtained as $69.542 \%$. General Cronbach alpha value of fitness center scale is .818. When regarded from sub factors, these values are .813 for lightening and ambiance and .818 for facility esthetics. In general, it can be said that Cronbach alpha values of factors of fitness center atmosphere are at the reliable level for the studies of social sciences (11).

\section{Correlation analysis}

Correlation analysis carried out to examine the one-to-one relationships between variables shows us that there are the relationships at dual level and at the significant level of $\mathrm{p}<0.01$ and $\mathrm{p}<0.05$.

As a result of correlation analysis, it is seen that correlation coefficient between the sub dimensions of satisfaction and atmosphere, significantly and positively but not so strongly affected the variables of ambiance and lightening ( $\mathrm{p}=0.377$ ), and esthetics of fitness center (0.357). In addition, it is seen that satisfaction positively and significantly affected the variable of loyalty $(0.322)$.

Table 2. Factor and variables of fitness center atmosphere for variance.

\begin{tabular}{|c|c|c|c|c|}
\hline Factor and Variables of Fitness Center Atmosphere & Factor Load & Eigen value & $\begin{array}{l}\text { The rate of accounting for } \\
\text { variance }\end{array}$ & $\begin{array}{c}\text { Cronbach's } \\
\text { Alfa }\end{array}$ \\
\hline Factor 1-Ambiance and Lightening & & 3.553 & 44.415 & 0.813 \\
\hline Lightening of sport center created a comfortable atmosphere. & .912 & & & \\
\hline Lightening of sport center gave a good welcoming feeling. & .841 & & & \\
\hline Lightening of sport center created a warm atmosphere. & .830 & & & \\
\hline Temperature level in sport business was a suitable level. & .805 & & & \\
\hline Factor 2- Faculty Esthetics & & 2.010 & 25.127 & 0.878 \\
\hline In sport center, paintings and pictures were interest attractive. & .875 & & & \\
\hline Wall decorations of sport center were visually interesting. & .830 & & & \\
\hline The colors in sport center formed a warm atmosphere. & .821 & & & \\
\hline The playing music in sport center stimulates me. & .650 & & & \\
\hline
\end{tabular}

Variance accounted for : 69.542; KMO: 0.789; Bartlett Test $\mathrm{p}<.000$ 
Table 3. Pearson correlations for the study variables.

\begin{tabular}{clcccc}
\hline & \multicolumn{1}{c}{1} & 2 & 3 & 4 \\
\hline 1 & Ambiance/ & - & & & \\
2 & Lightening & & & & \\
2 & Facility Esthetics & $.274^{* *}$ & - & & \\
3 & Satisfaction & $.377^{* *}$ & $.357^{* *}$ & - & \\
4 & Loyalty & $.268^{* *}$ & $.203^{* *}$ & $.322^{* *}$ & - \\
\hline${ }^{*} \mathrm{p}<.05,{ }^{* *} \mathrm{p}<.01$. & & &
\end{tabular}

\section{Regression Analyses}

In regression analysis, carried out to examine how atmosphere of fitness center affected satisfaction and satisfaction, the variable of behavioral loyalty, the relationships between satisfaction and fitness center, ambiance and lightening, and esthetics of fitness center, among the sub dimensions of atmosphere, and between satisfaction and loyalty are examined.

Table 3. Regression analysis regarding the effect of the dimensions of fitness center atmosphere on satisfaction.

\begin{tabular}{|c|c|c|c|c|}
\hline \multicolumn{2}{|c|}{ Independent Variables } & $\beta$ & $\mathrm{t}$ & $\mathrm{p}$ \\
\hline \multicolumn{2}{|c|}{ Ambiance- Lightning } & .301 & 7.301 & .000 \\
\hline \multicolumn{2}{|c|}{ Facility Esthetics } & .275 & 6.655 & .000 \\
\hline $\mathrm{R}^{2}$ & $\mathrm{~F}$ & $\mathrm{p}$ & \multicolumn{2}{|c|}{ Durbin-Watson } \\
\hline .212 & 67.136 & .000 & \multicolumn{2}{|c|}{1.733} \\
\hline
\end{tabular}

When Table 3 is examined, it is possible to express that regression model, established as a result of the values found $\mathrm{p}=0.000$ at the level of $\mathrm{F}=$ 67.136 regarding model is significant as a whole. The value $\mathrm{R}^{2}$ expresses how many percentage part of dependable variable are explained by independent variables. Durbin-Watson test is a statistics used for controlling the precondition of independence of error terms and shows whether or not there is autocorrelation in the model. In Durbin-Watson test, the values 1.5-2.5 shows that there is no autocorrelation (24). According to this, it was seen that the rate of independent variables, which takes place in the model, to account for dependent variable was $21.2 \%\left(R^{2}=2.12\right)$. The value of DubinWatsom is 1.733. While F statistics is used to test whether or not model is significant, t-statistics is used to individually test whether or not the variables are significant. Beta $(\beta)$ shows the significance order or independent variables. The variable having the highest $\beta$ value is relatively the most significant variable (24).

According to this, at the significant level of $\mathrm{p}<$ .05 , it is seen that there is positively $(\beta=.301)$ and significantly (.000) relationship between the dimension of ambiance / lightening of fitness centers atmosphere and satisfaction. It is seen that there is positively $(\beta=.275)$ and significantly (.000) relationship between the dimension "facility esthetics" of fitness centers atmosphere and satisfaction. According to the findings obtained, the findings obtained shows that $21.2 \%$ of the variation in the variables of satisfaction is accounted for by the factors forming the conditions of fitness center atmosphere (Fitness center ambiance/lightening and fitness center esthetics). It is seen that the dimension of atmosphere conditions that are the most effective on satisfaction is the factor of fitness center ambiance/lightening (Beta=0.301)

Table 4. Regression analysis regarding the effect of loyalty on satisfaction.

\begin{tabular}{cccccc}
\hline \multicolumn{3}{l}{ Independent Variables } & $\beta$ & $\mathrm{t}$ & $\mathrm{p}$ \\
\hline \multicolumn{2}{l}{ Loyalty } & & .322 & 7.617 & .000 \\
\hline $\mathrm{R}^{2}$ & $\mathrm{~F}$ & $\mathrm{p}$ & \multicolumn{3}{l}{ Durbin-Watson } \\
.104 & 58.013 & .000 & \multicolumn{3}{l}{1.595} \\
\hline
\end{tabular}

According to the findings taking place in Table 4 , the values of $F=58,013$ and $p=, 000$ show that the regression model established is significant as a whole. It is seen that the rate of the independent variables taking place in model to account for the dependent variable is $10.4 \%\left(\mathrm{R}^{2}=.104\right)$. The value of Durbin-Watson realized as 1.595.

According to the findings regarding the regression analysis carried out it is seen that there is a positive directional $(\beta=$.322) relationship between loyalty and satisfaction.

In the framework of situational model, the findings regarding the model tested are given in the following Figure 2.

In the framework of institutional model, when the findings regarding the model tested are evaluated, it was identified that fitness center atmosphere ambiance/lightening (Beta=0.301) and esthetics (Beta $=0.275)$ affected customer satisfaction and satisfaction, loyalty (Beta=0.322). According to this, it is possible to express that as the perceptions of ambiance/lightening and esthetics of fitness center customers' increase, their satisfaction levels will increase, and as their satisfaction levels increases, loyalty will also increase. 


\section{Atmosfere}

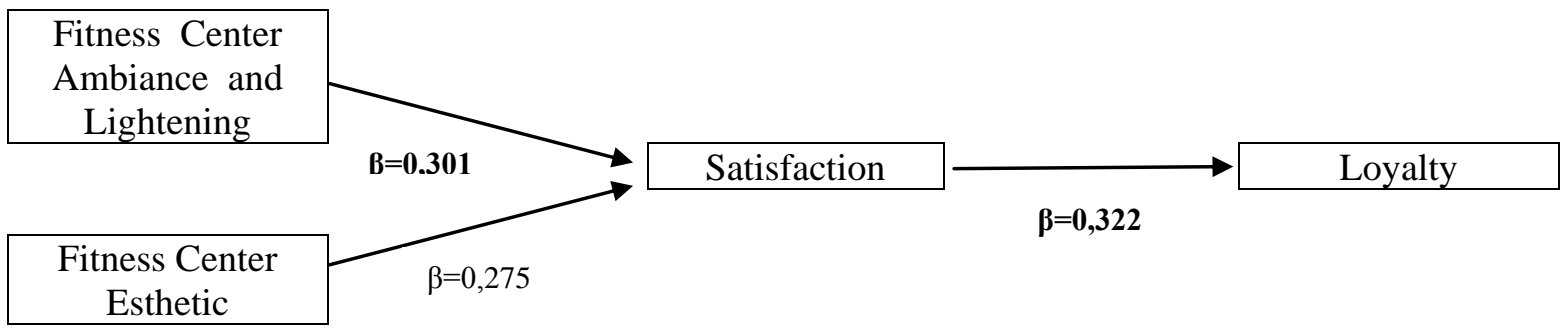

\section{DISCUSSION}

The expectations and participation causes of each customer coming to fitness centers are different from each other. Some of them participate in the program to reach healthy life; some, to let off steam, and some, to completely lose weight (14). But, it is considerably important to make physical activity and sport in an enjoyable environment, in which good service is presented, because spending a time in sport centers having a good medium presents a nice experience to the people. As a result of these experiences of people, their intensions such as visiting again the same fitness center and recommending it to their friends are shaped. It is considered that that fitness centers realize this aim depends on the atmosphere they create, because time of a customer to stay in sport center, the satisfaction he/she experiences, and his/her behaviors regarding loyalty, based on this, depend on the environment a sport center forms. Leisure time evaluation, physical activity and sport medium, presented by a sport center to its customer, are important determinants of competitive level. Therefore, it is not enough to design quality of sport center only tangibly. Beside this, that the atmosphere of sport center positively affects the emotional state of customer is also important. While it is possible for the other sport center to be able imitate the design and quality criteria of a sport center more easily, the atmosphere formed can differentiate. The study is grounded in the direction of this viewpoint. When the literature on the area is reviewed, the lack of such a study, previously carried out, in fitness sector reflects the quality of this study to become a pioneer. Depending on this, the relationships between the variables and evaluations were formed by utilizing the studies carried out on the different service sectors.

As a conclusion of the study, it can be said that fitness center atmosphere is effective on satisfaction.
It was seen that especially ambiance/lightening were more effective on satisfaction compared to facility esthetics. In other words, the effect of emotions such as "that lightening sport center gives a good welcoming feeling" and that "lightening sport center creates a warm atmosphere" on satisfaction are more than the emotions such as "that paintings or photographs in sport center are interesting", and that "music played in sport center stimulate customers". In the light of these results, it can be deducted the meaning that when customers go to fitness center to receive service, they have more positive emotions with the effect of more ambiance/lightening and facility esthetics. When regarded to the similar studies, carried out on the subject and supporting our study findings, it was identified that ambiance/lightening and facility esthetics had the direct and indirect effects on satisfaction. Kim and Moon (28), in their studies they carried out on restaurant businesses, stated that getting service, which consist of ambiance conditions, arrangements of facility esthetics, electrical gadgets, and sitting comfort, formed satisfaction feeling on customer. In addition, Baker et al (3), in the study they carried out on the retailing stores, suggested that in-store atmosphere positively affected social dimension and consumer's taking action. In addition, it was found that the variable interaction $(A \times S)$ derived from the dimensions social (S) and ambiance (A) positively affected consumer satisfaction. As a result of the study, it was identified that the emotions of satisfaction and taking action positively affected purchasing desire. Sherman et al. (43) stated that the dimensions social and design of in-store atmosphere had a positive effect on satisfaction. Ryu and Jang (41), in the study carried out on restaurant business, [identified] that while internal design, ambiance, and order affected satisfaction feeling, satisfaction feeling also positively affected behaviora intention. Morrison et al (35) stated that the dimension music, one of the sub factors of the dimension ambiance of 
in-store atmosphere, positively affected consumer satisfaction and his/her taking action emotions.

It was identified that loyalty was affected from customer satisfaction at high level. The relationship between satisfaction and loyalty is positive directional and increase in satisfaction also affects the future emotions of customers. In the customer, whose satisfaction level increase, the behaviors of revisiting, more frequently visiting, positively advertising about business, and accepting to pay more can also increase. In the literature on sport business, it is seen that the relationship between these two variables is examined, and that the satisfaction affects one or a few variables related to loyalty in positive direction $(8,21,26,51)$. The increase of positive behaviors in the future is important for sake of providing continuity of fitness center and obtaining competitive advantage.

This study can cause the importance of atmosphere to be better understood for fitness centers in mastering satisfaction and loyalty behavior in the future. Thanks to this, for sport and fitness centers, a set of result were obtained, which will increase customer satisfaction, and thus, affect customer loyalty.

The managers of fitness centers should, first of all, deal with the problems of sport centers associated with ambiance and lightening. Fitness centers should select a lightening compatible with waiting room, reception desk, at which customers are met; sort of sport program, and the hours, when the center is in active, whereby the ambiance felt will enable customers to feel themselves more comfortable. Ambiance and lightening also affect satisfaction. The temperature of fitness center became a subject dealt with in the dimension ambiance. That temperature level is well adjusted was seen as important in terms of both customers participated in physical activities and in waiting room on this issue, the necessary actions should be taken.

While customers evaluate esthetics of fitness, center, they saw the paintings, photographs, decoration, and music as a part of esthetics. That all of these esthetic elements constitute integrity is considerably important in such a way that it will be compatible with the theme of sport center. If managers of fitness center do not select the wall decorations they use, paintings, and music in such a way that they will complete each other, fitness center will both be confusing and customer will not be able to fully experience the medium he/she desires and dissatisfaction will occur. The individuals, who have positive feelings toward fitness center, will make a long termed contact and this state will be in favor of both fitness center and customer. Satisfaction these state beings together with it will provide loyalty

According to the results of the study, the suggestions for the future studies are summarized as follows in items:

$\checkmark$ When literature is taken into consideration, any study is not met focused on the sensory evaluations of customer regarding atmosphere of service area or particularly fitness center atmosphere. Therefore, that the future researchers deal with this subject will be useful.

$\checkmark$ In his study, the dimensions of fitness center are taken as only ambiance/lightening and esthetics. In future, the studies, in which the dimensions such as the general plan/design of the facility, complexity/order, service presentation, and cleanness, etc. are also evaluated together, should be carried out. In addition, beside the variables of atmosphere, in the context of the different stimulators such as satisfaction, and loyalty, campaigns, image of fitness center, emotional state before getting service, intention, presence of those peoples making sport, it can be recommended that researchers make an attempts of modeling.

$\checkmark$ Finally, that the researchers concentrate on the views of customers, who have the different demographic characteristics, regarding fitness center atmosphere, their satisfactions, and loyalties will make a contribution to the literature.

\section{REFERENCES}

1. Alexandris K, Zahariadis P, Tsorbatzoudis C, Grouios G. An empirical investigation of the relationships among service quality, customer satisfaction and psychological commitment in a health club context. European Sport Management Quarterly, 2004; (4): 36-52.

2. Aslan M, Koçak MS. Determination of the service quality among sport and fitness centers of the selected universities. Journal of Human Sciences, 2011; 8(2): 817-833.

3. Baker J, Levy M, Grewal D. An experimental approach to making retail store environmental decisions. Journal of Retailing, 1992; 68(4): 445-460.

4. Bakırtaş H. Importance in marketing of store atmosphere and emotion at S-O-R paradigm fundamental: A literature review. KMU Journal of Social and Economic Research, 2013; 15 (25): 47-55. 
5. Bauer HH, Stokburger-Sauer NE, Exler S. Brand image and fan loyalty in professional team sport: A refined model and empirical assessment. Journal of sport Management, 2008; 22(2): 205-226.

6. Bee CC, Kahle LR. Relationship marketing in sports: A functional approach. Sport Marketing Quarterly, 2006; 15(2): $101-110$

7. Beyer T. Determinanten der Sportrezeption. Erklarungsmodell uns kausalanalytische Validierung, Beispiel der Fussballbundesliga. 2006, Wiesbaden: Deutscher Uni. Verlag.

8. Biscaia R, Correia A, Rosado A, Maroco J, Ross S. The effects of emotions on football spectators' satisfaction and behavioral intentions. European Sport Management Quarterly, 2012; 12(3): 227-242

9. Bitner MJ. Servicescapes: The impact of physical surroundings on customers and employees. The Journal of Marketing, 1992: 56(2); 57-71.

10. Bruhn M. Unternehmens-und Marketingkommunikation: Handbuch für ein integriertes Kommunikationsmanagement. 2012, Vahlen

11. Büyüköztürk Ş, Kılıç Ç, Akgün ÖE, Karadeniz Ş, Demirel F. Bilimsel Araştırma Yöntemleri. 2012: 11. Basım, Ankara, Pegem Yayınları.

12. Chelladurai P. Human Resource Management in Sport and Recreation. 1999, Human Kinetics, Champaign, II.

13. Gambarov V. Atmosphere in retail stores: Research on factors affecting the consumers retail store choices in Azerbaijan. 2007, Dokuz Eylül University, Social Sciences Institute.

14. Girginer N, Fiahin B. A case study of simulation for queuing problem in the fitness centers. Hacettepe J. of Sport Sciences , 2007; 18 (1): 13-30.

15. Greenwell TC. Expectations, industry standards, and customer satisfaction. 2007.

16. Ha J, Jang SC. Effects of service quality and food quality: The moderating role of atmospherics in an ethnic restaurant segment, International Journal of Hospitality Management, 2010; 29: 520-529.

17. Han $\mathrm{H}$, Ryu K. The roles of the physical environment, price perception, and customer satisfaction in determining customer loyalty in the restaurant industry, Journal of Hospitality \& Tourism Research, 2009; 33: 487-510.

18. Heinemann K. Einführung in die Ökonomie des Sports. Ein Handbuch. 1995, Schorndorf, Hofmann.

19. Hermanns A, Riedmüller F. Sport und Unterhaltung. Eine neue Dimension. In: Hermanna, Arnold, Riedmüller, Florian(Hg): Management Handbuch Sport Marketing, München, Vahlen 2001; 687-696.

20. Heung VCS, Gu T. Influence of restaurant atmospherics on patron satisfaction and behavioral intentions. International Journal of Hospitality Management, 2012; 31; 1167-1177.

21. Howat G, Murray D, Crilley G. The relationship between service problems and perceptions of service quality, satisfaction and behaviroural intentions of Australian public sports and leisure center customers, Journal of Park and Recreation Administration, 1999; 17(2); 42-64.
22. http://www.dssv.de/home/statistik/fitness-in-europa/ 10.10.2016.

23. Jung GM. Structural Equation Modeling Between Leisure Involvement, Consumer Satisfaction, and Behavioral Loyalty in Fitness Centers in Taiwan. 2007, ProQuest Dissertations and Theses.

24. Kalaycı Ş. SPSS Uygulamalı Çok Değişkenli İstatistik Teknikleri, 2009, Asil Yayın Dağıtım, Ankara.

25. Karasar N. Bilimsel Araştırma Yöntemi. 2009, Ankara, Nobel Yayın Dağıtım.

26. Katırc1 H, Oyman M. Customer satisfaction and loyalty in sport centers. Niğde University Journal of Physical Education and Sports Science, 2011; 5(2): 90-100.

27. Kennett AK. Showmethemoney Check Cashers, Inc. v. Williams: Show Me the Mutuality-A New Demand Based on an Old Doctrine Changes the Rules for Enforceability of Arbitration Agreements in Arkansas. Ark L Rev, 2001; 54, 621.

28. Kim D, Kim SY. QUESC: An instrument for assessing the service quality of sport centers in Korea. Journal of Sport Management, 1995; 9: 208-220.

29. Kim WG, Moon YJ. Customers' cognitive, emotional, and actionable response to the service scape: A test of the moderating effect of the restaurant type. International Journal of Hospitality Management, 2009; 28(1); 144-156.

30. Kotler P, Bliemel F. Marketing-Management, 2001,10., Überarbeitete und aktualisierte Auflage. Stuttgart: SchäfferPoeschel.

31. Kotler P. Atmospherics as a marketing tool. Journal of Retailing, 1973; 49(4): 48-64.

32. Krafft M, Klingsporn B, Götz O, Hoffmann A, Scheer B, Schurk V. Kunden Karten. Kundenkartenprogramme erfolgreich gestalten. 2007, Online unter URL: http://www. marketing-centrum.

de/ifm/kundenkarten/Leseprobe_Kundenkarten.

33. Lapa TY, Baştaç E. Evaluating the service quality assessment of individuals attending fitness centers in Antalya. Pamukkale Journal of Sport Sciences, 2012; 3(1): 4252 .

34. Liu Y, Jang, SS. Perceptions of Chinese restaurants in the US: What affects customer satisfaction and behavioral intentions? International Journal of Hospitality Management, 2009; 28(3): 338-348.

35. Morrison M, Gan S, Dubelaar C, Oppewal H. In-Store music and aroma influences on shopper behavior and satisfaction. Journal of Business Research, 2011; 64(6): 558-564.

36. Okuneva D, Gavrilov V, Muzika V. Torgovom Zale Zastavlyayet Posetiteley Bolşe Tratit. 2005, Novie İzvestiya, 8: 175, 27.12. Moskova, Rusya.

37. Oliver RL. Whence consumer loyalty? The Journal of Marketing, 1999; 33-44.

38. Öztürk H, Adiloğulları İ, Ay SM. An investigation of satisfaction levels of customers in healthy lifestyle and fitness center in terms of some demographic variables. Journal of CBU Physical Education and Sport Sciences, 2014; 6(2): 31-38.

39. Parasuraman A, Zeithaml VA, Berry LL. A conceptual model of service quality and its implications for future research. Journal of Marketing. 1985; 49(4): 41-50. 
40. Rohlmann P, Schewe G. Aktuelle Entwicklungen und Tendenzen im Sportmarketing. 2005, In: Schewe, Gernand Rohlmann, Peter (Hg): Sportmarketing. Perspektiven und Herausforderungen vor dem Hintergrund des Fussball-WM 2006. Schorndorf: Hofmann S. 3-16.

41. Ryu K, Jang S. Influence of restaurants' physical environment on emotion and behavior intention. The Service Industries Journal, 2008; 28(8): 1151-1165.

42. Savaş N. Service quality, costemer satisfaction and customer loyalty: A research on the fitness centre members. 2012, Balıkesir University, Social Sciences Institute. Balıkesir.

43. Sherman E, Marthur A, Smith B. Store environment and consumer purchaise behaviour: Mediating roler of consumer emotions. Psychology and Marketing, 1997; 14(4): 361-378.

44. Soygüden A, Kaya S, Hoş S. Investigation of intended service quality levels in health-fitness centers in Turkey. Niğde University Journal of Physical Education And Sport Sciences, 1997; 9(1):163-178.

45. Sulek JM, Hensley RL. The relative importance of food, atmosphere, and fairness of wait: The case of a full-service restaurant. Cornell Hotel and Restaurant Administration Quarterly, 2004; 45(3): 235-247.

46. Triado XM, Aparicio P, Rimbau E. Identification of factors of customers satisfactions in municipal sport centers in
Barcelona: Some suggestions for satisfaction improvement. Cyber Journal of Sport Marketing, 1999; 13: 34-61.

47. Ünal S, Akkuş G, Akkuş Ç. The relationship between the atmosphere, emotion, satisfaction and behavioral intention in the food and beverage enterprises. Gazi University Journal of Tourism Faculty, 2014: 1; 23-49.

48. Welling M. Das Produkt Fußball? Eine leistungstheoretische Grundlegung zur Identifikation von Produktions- und Absatzspezifika. In :Reckenfelderbaumer, Martin; Welling, Micheal(Hg): Fußball als Gegenstand der Betriebswirtschaftslehre. Leistungstheoretische und qualitatspolitische Grundlagen. Lahr,2003: 5-46.

49. Yetim G. The effect of leisure involvement on leisure satisfaction and loyalty: A study on fitness centers in Eskişehir. 2014, Anadolu University, Health Sciences Institute. Eskişehir.

50. Yıldız SM, Tüfekçi Ö. Assessment of expectations and perceptions of fitness center customers for service quality. The Journal of Social Sciences Institute, 2010; 13(24): 1-11.

51. Yildiz Y. Investigation of the affect of the customer satisfaction on the customer loyalty in fitness centers. Selçuk University Journal of Physical Education and Sport Science, 2012: 14 (2): 217-222. 